\title{
- Manejo e enfermidades de quelônios brasileiros no cativeiro doméstico
}

\section{- Management and disease of Brazilian chelonians in urban captivity}

\author{
* Francis Magno Flosi ${ }^{1}$-CRMV-SP- $\mathrm{n}^{0} 3154$ \\ Jerusa Martins Garcia ${ }^{2}$ \\ Claudete Pugliese ${ }^{3}$ \\ AndreaAranhaSanche $z^{3}$ \\ Aparecido Klai ${ }^{2}$
}

1 Docente do Curso de Medicina Veterinária da Universidade do Grande ABC/SP.

${ }^{2}$ Discentes de Medicina Veterinária da Universidade Metodista de São Paulo/SP.

${ }^{3}$ Discentes do Curso de Medicina Veterinária da Universidade do Grande ABC/SP.

\section{RESUMO}

Os quelônios brasileiros encontram-se agrupados nas famílias Testudinidae (jabutis); Chelidae, Emydidae, Pelomedusidae, Kinosternidae (cágados e tracajás). Muitas espécies dessas famílias são mantidas em cativeiro doméstico, necessitando de um manejo adequado pelos seus proprietários. Dentro do manejo podemos citar, como ponto principal, a correta nutrição destes animais, por meio de alimentos balanceados de acordo com as necessidades de cada espécie. Desse modo, estaremos evitando uma série de enfermidades induzidas pelo incorreto manejo como, por exemplo, as tão freqüentes deformações da carapaça e as hipovitaminoses, principalmente a hipovitaminose A. Ressalta-se, ainda, a necessidade da preservação desses animais, bem como a de seu ecossistema.

Palavras-chave: quelônios, manejo, alimentação, doenças.

\section{Introdução}

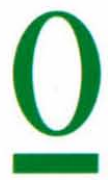

s quelônios, animais popularmente denominados de tartarugas, têm características muito particulares que os diferenciam claramente dos répteis. Encontram-se cobertos por uma carapaça muito dura, dentro da qual podem, a maioria deles, recolher sua cabeça e seus membros (BIANCO et al., 1959). As cinturas escapular e pélvica inteiras encontram-se incorporadas dentro do casco ósseo, uma característica anatômica apresentada somente neste grupo animal (BIRCHARD e SHERDING, 1998). Em suas mandíbulas possuem peças bucais em forma de córneas cortantes no lugar de dentes. Dotados de quatro patas que, quando adaptadas para caminhar, têm cinco dedos, e quando adaptadas para nadar, têm o formato de paleta. Habitam normalmente zonas tropicais e temperadas. São ovíparos e depositam seus ovos no solo, onde cavam e os enterram. Podem ser herbívoros ou carnívoros (BIANCO et al., 1959). 


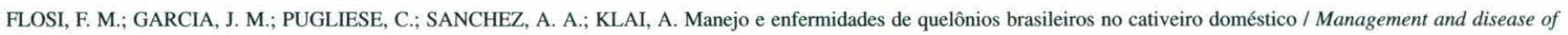
Brazilian chelonians in urban captivity. / Rev. educ. contin. CRMV-SP / Continuous Education Journal CRMV-SP, São Paulo, volume 4, fascículo 2, p. 65 - 72, 2001.

Fazem parte do filo Chordata, classe Reptilia, ordem Chelonia, sub ordem Cryptodira, abrangendo as famílias Testudinidae, Chelidae, Emydidae, Kinosternidae e Pelomedusidae (FRANCISCO, 1997).

Na família Testudinidae estão os jabutis que vivem no meio terrestre e que, no Brasil, são encontrados nas regiões Norte e Central (SAÚDE ANIMAL, 2000).

Popularmente inclusos num mesmo grupo, o de tartarugas de água doce, os cágados (família Chelidae) e tracajás (família Pelomedusidae), habitam principalmente rios e lagos de água doce. São encontrados de norte a sul do país (SANTOS, 1994; HÖFLING et al., 1995).

A família Emydidae compreende espécies aquáticas e semi-aquáticas como o tigre-d'Água (Trachemys dorbigni) e a aperema (Rhinoclemmys punctularia). Há também a família Kinosternidae, com a espécie Kinosternon scorpioides (muçuã), presente nas regiões Norte e Nordeste do Brasil (SOCIEDADE DE ZOOLÓGICOS DO BRASIL, 1991).

De um modo geral, todas as espécies correm risco de extinção diante das alterações ambientais provocadas pelas atividades de produção agrícola, pecuária, industriais e extrativistas, desenvolvidas pelo homem (SPALATO, 1999; CENERINO, 2000).

$\mathrm{Na}$ bacia do rio Amazonas, por exemplo, ocorre a captura desses animais para o consumo da carne e da gordura. Os ovos de tracajás são coletados para se preparar o abunã, uma iguaria feita como pirão, com farinha de mandioca (HOUAISS, 1979).

Os ovos de jabutis são empregados no preparo de manteiga e óleo combustível usado para iluminação (SANTOS, 1994).

Além disso, muitos indivíduos são capturados para serem comercializados como animais de estimação o que, somado ao fato de seu habitat ser progressivamente invadido e alterado pela presença e pelas atividades humanas, muito tem contribuído para a redução da população desse e de outros filos, sejam do reino animal, sejam do reino vegetal (MOLINA, 1999; SPALATO, 1999; CENERINO, 2000).

Este trabalho teve por objetivo reunir algumas informações sobre o manejo de quelônios brasileiros no cativeiro doméstico, bem como suas principais enfermidades e, principalmente, destacar a importância da sua preservação em seu habitat.

\section{Jabutis, Cágados, Tracajás e suas características}

\section{O jabuti}

O jabuti pertence ao filo Chordata, classe Reptilia, ordem Chelonia, subordem Cryptodira, família
Testudinidae, gênero Geochelone (HÖFLING et al., 1995).

As espécies brasileiras são o Geochelone denticulata (Figura 1), popularmente conhecido por jabutitinga e Geochelone carbonaria, conhecido como jabutipiranga ou jabuti-das-patas-vermelhas por possuir escamas vermelhas na cabeça e nas patas (FARIA, 2000).

Suas patas normalmente não possuem um movimento de pulso ou tornozelo identificável; essas articulações encontram-se enrijecidas. As patas anteriores possuem garras grandes, que ficam rombas em função do apoio em deslocamentos sobre essas garras. As patas posteriores são semelhantes a tocos, com solas achatadas, lembrando patas de elefante (SANTOS, 1994).

Seu corpo é envolvido por um par de cascos ósseos. O casco de cima é chamado de carapaça e, através da evolução, incorporou o gradil costal. A placa de baixo é chamada de plastrão (BIRCHARD et al., 1998; FARIA, 2000).

O jabutipiranga (Geochelone carbonaria) pesa de 6 a 12 quilos. Os machos medem em média $30,4 \mathrm{~cm}$; as fêmeas $28,9 \mathrm{~cm}$. Atinge a maturidade sexual entre os 5 e 7 anos. Em cada postura, as fêmeas ovipõem 6 ou 7 ovos, muito embora alguns autores mencionam posturas de 15 a 20 ovos (SAÚDE ANIMAL, 2000).

O G. carbonaria é encontrado na América do Sul (Guianas, Venezuela, Equador, Paraguai e Brasil) e em algumas ilhas do Caribe. Contudo, apesar dessa ampla distribuição geográfica, é um gênero que carece de um maior interesse pelos pesquisadores (FARIA, 2000).

Os machos de jabutitinga (Geochelone denticulata) são menores que as fêmeas, atingindo cerca de 40 $\mathrm{cm}$ de comprimento; enquanto as fêmeas chegam até 70 $\mathrm{cm}$. Seu peso ideal, idade de maturidade sexual, número de ovos, período de incubação e tempo de vida são semelhantes ao jabutipiranga (SAÚDE ANIMAL, 2000) Caracteriza-se por uma coloração em geral mais clara que a do Geochelone carbonaria. A denominação denticulata provém dos dentículos que os filhotes apresentam nas bordas das escamas marginais da carapaça. À medida que os animais vão-se desenvolvendo, perdem os dentículos, mas conservam o colorido amarelado (FRANCISCO, 1997).

É nitidamente maior que o Geochelone carbonaria, sendo, na verdade, a maior espécie de jabuti da América do Sul e habita florestas densas.

O jabuti é um animal essencialmente terrestre, porém sabe nadar, embora não mergulhe, e aprecie bem um banho demorado (SANTOS, 1994).

Em geral os jabutis apresentam uma carapaça alta e ornada de escudos poligonais com desenhos em relevo. 


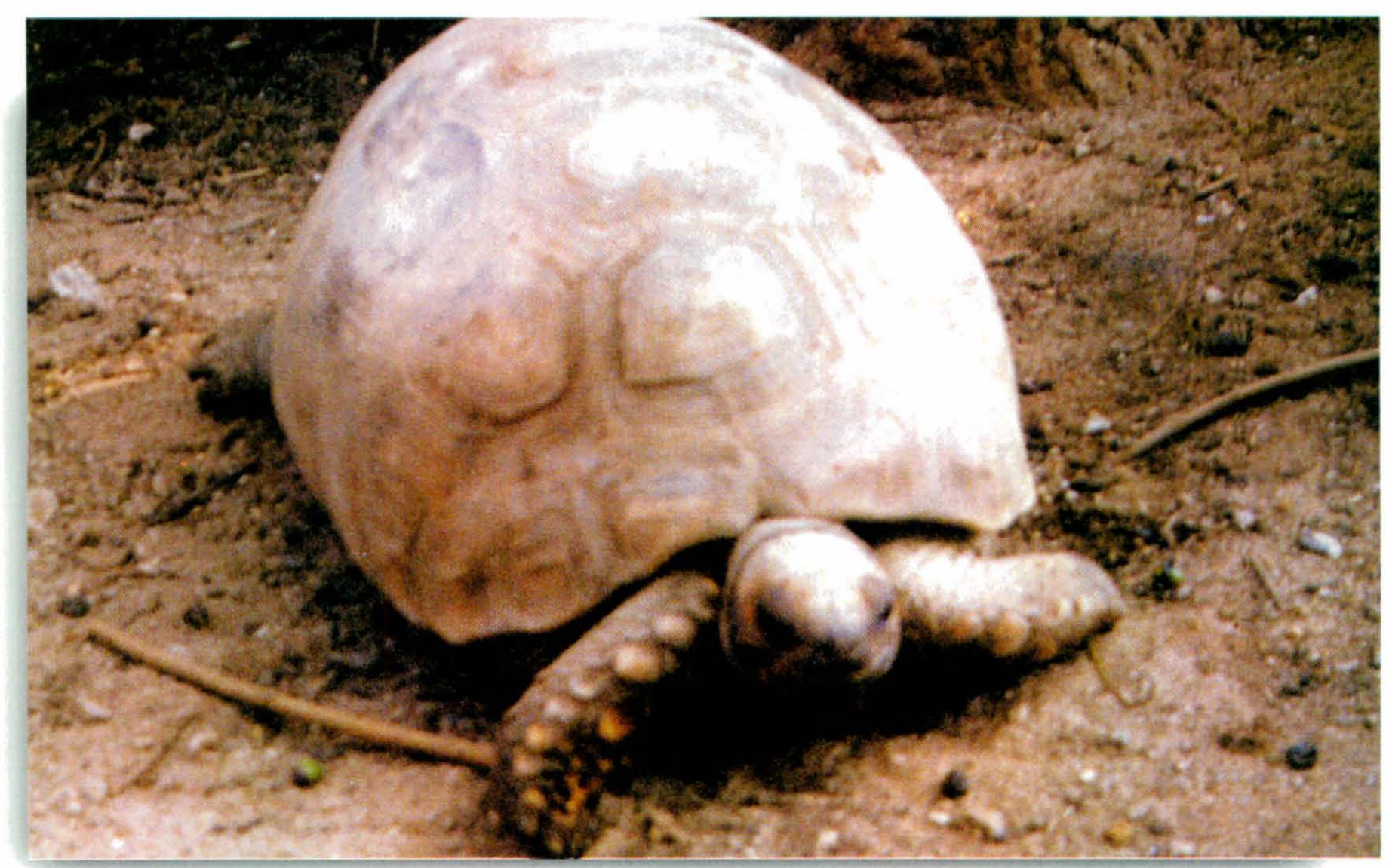

Figura 1. Geochelone denticulata (Foto tirada na Escola de Ecologia de São Caetano do Sul-SP).

Sua cabeça é retrátil, achatada dorsalmente e revestida de placas córneas (HÖFLING et al., 1995).

A extremidade anterior da maxila é curvada para baixo, ultrapassando um pouco a mandíbula, formando um bico córneo (HÖFLING et al., 1995). Seu pescoço é curto e rugoso. Suas patas são retrateis e robustas (SANTOS, 1994).

A fêmea, denominada de jabota, difere do macho por ser maior e possuir o plastrão plano, ao contrário do macho que possui um plastrão côncavo para facilitar a cópula (SANTOS, 1994; BIRCHARD e SHERDING, 1998).

A carne do jabuti é consumida e apreciada e seus ovos, redondos e brancos, são utilizados no preparo de manteiga e óleo combustível (BIANCO et al., 1959; SANTOS, 1994).

\section{Cágados e Tracajás}

Pertencem ao filo Chordata, classe Reptilia, ordem Chelonia, subordem Cryptodira, famílias Chelidae, Emydidae, Kinosternidae e Pelomedusidae (FRANCISCO, 1997).

Na família Chelidae encontramos os gêneros Phrynops, Acantochelys, Hydromedusa, Platemys e Chelus, tendo as seguintes espécies: Phrynops tuberculatus (cágado-cabeçudo), Phrynops geoffroanus (cágado-de-bar- bicha), Phrynops hilarii (cágado-da-lagoa), Acantochelys spixii (cágado-feio), Hydromedusa tectifera (cágado-pescoço-de-cobra), Platemys platycephala (jabuti-machado) e Chelus fimbriatus (matamatá) (FRANCISCO, 1997).

A família Emydidae apresenta dois gêneros: Rhinoclemmys, com a espécie $R$. punctularia (aperema) e Trachemys, com a espécie $T$. dorbigni (tigre-d'água) (FRANCISCO, 1997).

A família Kinosternidae apresenta o gênero $K i$ nosternon com a espécie brasileira $K$. scorpioides (muçuã) (FRANCISCO, 1997).

A quarta e última família, Pelomedusidae, apresenta dois gêneros no Brasil: Podocnemis, com as espécies $P$. expansa (tartaruga-da-amazônia) e $P$. unifilis (tracajá); e o gênero Peltocephalus (FRANCISCO, 1997).

Cágados e tracajás são quelônios cujo habitat inclui o ambiente aquático dos rios, lagos rasos e terrenos pantanosos (FARIA, 2000).

Entre as características morfológicas que vão diferenciá-los do grupo anterior estão os membros, que possuem dedos distintos unidos por membrana que lhes facilita a natação, e a carapaça, mais baixa e mais arredondada (SANTOS, 1994). 
Cágados são encontrados de norte a sul do País. Na região Sul destacam-se duas espécies: Chrysemys dorbigni, muito abundante no Rio Grande do Sul encontrados também na Argentina e no Uruguai e o Phrynops geoffroanus, conhecido como cágado-de-barbicha, encontrado na região Sul do Brasil, na Argentina, no Uruguai e no Paraguai (VEITENHEIMER-MENDES, 1993; FRANCISCO, 1997).

Os cágados têm como característica recolher sua cabeça, com movimento lateral para dentro da carapaça (SANTOS, 1994).

Na região do Amazonas, tanto a carne quanto os ovos do tracajá são bastante apreciados (SANTOS, 1994). Os ovos de tracajás são coletados para o preparo de abunã, uma iguaria feita como pirão, com farinha de mandioca (HOUAISS, 1979).

Os tracajás recolhem sua cabeça totalmente, com movimento vertical, para dentro da carapaça (SANTOS, 1994).

\section{Manejo de quelônios}

Os quelônios mais comumente mantidos em cativeiros são os cágados e jabutis e sua contenção não representa maiores problemas. Os cágados normalmente não atingem grandes proporções e, em geral, podem ser facilmente manuseados, muito embora, por vezes, suas unhas arranhem aquele que os está manipulando (FRANCISCO, 1997).

Uma dificuldade na contenção de cágados reside no fato de que algumas espécies recolhem o pescoço para o lado e para dentro da carapaça. Se for necessário que o pescoço do animal seja colocado para fora, basta segurar uma dobra da pele do pescoço com uma pinça e manter o animal suspenso. Sustentando o corpo com o pescoço, pouco a pouco o animal vai cedendo ao peso do próprio corpo, terminando por relaxar o pescoço e, conseqüentemente, colocando-o para fora (FRANCISCO, 1997).

Os jabutis, por outro lado, podem atingir em média $70 \mathrm{~cm}$ quando adultos e pesar mais de 30 quilos. Em razão disso, às vezes, pode ser complicado sustentar esses animais nas mãos. Pesados ou não, contudo, os jabutis devem ser seguros pelos lados da carapaça. Se contidos por muito tempo nas mãos, têm o hábito de urinar e defecar, como forma de defesa. Uma maneira bastante prática para conter um jabuti é utilizando um objeto cilíndrico, como uma lata de leite em pó. Essa lata, colocada embaixo do animal, impede-o de se deslocar, pois seus membros estarão suspensos (FRANCISCO, 1997).

\section{Alimentação}

Todos os animais necessitam de alimentos para se desenvolver e como fonte de energia para a manutenção do organismo (WOOD, 1973). A falta de determinado nutriente faz com que o organismo mobilize suas reservas (ANGELIS, 1979). Assim, uma alimentação que não contenha todos os minerais e vitaminas necessários ao organismo do animal pode levar ao aparecimento de alguns males (MAYNARD e LOOSLI, 1974).

Em seu habitat, o jabuti e o cágado, por se tratar de onívoros, alimentam-se de frutos, brotos, ovos, insetos, anelídeos e pequenos vertebrados (SANTOS, 1994).

Esses animais, quando em cativeiro, necessitam de uma dieta de qualidade e bem diversificada. Podem ser mantidos com carne moída, peixes, besouros, larvas e grilos. Os frutos podem ser dos mais variados, como uvas, abóboras, bananas, mamão, peras e maçãs. Podem receber verduras como a couve e o almeirão (MOLINA, 1999).

Necessitam ainda de um suprimento de cálcio, que pode ser fornecido pela farinha de osso. A quantidade de alimento varia de acordo com o tamanho do animal (FUNDAÇÃO PARQUE ZOOLÓGICO DE SÃO PAULO, s.d).

As espécies onívoras podem, ainda, receber uma alimentação preparada com ração canina seca ou enlatada como $50 \%$ da dieta, e deve-se oferecerlhes legumes e verduras, frutas, minhocas e insetos, equilibrando a dieta (BIRCHARD e SHERDING, 1998).

Já MADER (1996) relata que $85 \%$ da dieta deve ser composta de vegetais, $10 \%$ de frutas e apenas $5 \%$ de proteínas.

Pode-se alimentar os cágados e os jabutis adultos diariamente (BIRCHARD e SHERDING, 1998) ou em dias alternados (MADER, 1996; BIRCHARD e SHERDING, 1998). Filhotes devem ser alimentados diariamente (MADER, 1996).

Alguns jabutis (como os galápagos) são propensos a bócio, o que requer a adição de iodo Lugol, uma a duas gotas, uma ou duas vezes por semana, como preventivo (BIRCHARD e SHERDING, 1998).

Para espécies carnívoras aquáticas, é importante oferecer um alimento de origem animal tão variável quanto possível para um bom desenvolvimento ósseo (MOLINA, 1999).

Deve-se ofereçer vários peixes vivos inteiros, bem como insetos, minhocas e carne. Deve-se obter peixes de água doce de uma fonte limpa para evitar 


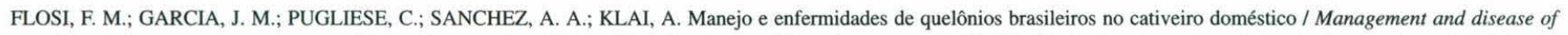
Brazilian chelonians in urban captivity. / Rev, educ. contin. CRMV-SP / Continuous Education Journal CRMV-SP, São Paulo, volume 4, fascículo 2, p. 65 - 72, 2001.

peixes portadores de doenças bacterianas ou parasitárias. Não se deve ofereçer peixes congelados em base regular, pois eles não têm vísceras e devem ser suplementados com vitamina $E$ e tiamina, em virtude da perda dessas vitaminas durante o processo de congelamento. Um pouco de material vegetal deverá ser oferecido também (BIRCHARD e SHERDING, 1998).

É melhor alimentar os quelônios aquáticos em uma área separada da instalação e limpar esse recinto semanalmente (BIRCHARD e SHERDING, 1998).

O comportamento alimentar é também influenciado pela luz. Se há uma iluminação inadequada, pode haver recusa do animal a alimentar-se, mesmo se a temperatura ambiental e outros fatores estiverem satisfatórios (FOWLER, 1986). Freqüentemente se necessita de uma exposição de 10 a 15 minutos de luz solar nãofiltrada ou lâmpada negra como estímulo psicológico do apetite nos jabutis (BIRCHARD e SHERDING, 1998).

Jabutis e tartarugas marinhas e aquáticas necessitam impreterivelmente de consumir água, cada qual a seu modo. Um grande perigo para os animais é a desidratação; é imperioso um fácil acesso à água (SCHMIDTNIELSEN, 1965).

A água é de importância vital para todos os seres vivos. A água ingerida pelo organismo animal participa da formação de tecidos durante a fase de crescimento e de todos os processos metabólitos do organismo (MAYNARD e LOOSLI, 1974).

A ingestão de água é feita também por meio dos alimentos; em contra partida, a perda de líquidos pelo organismo ocorre, além da via urinária, pelo suor, pelas fezes e pela respiração (SCHMIDT-NIELSEN, 1965).

A água é o constituinte mais importante do organismo animal, correspondendo a 50 a $60 \%$ de seu peso (ANGELIS, 1979).

\section{Reprodução}

A reprodução dos animais mantidos em terrários é a melhor prova de que os estamos mantendo em condições adequadas (FRANCISCO, 1997).

Nem sempre é possível identificar o sexo dos répteis, visto que em boa parte das espécies não há dimorfismo sexual e alguns caracteres sexuais externos são visualizados apenas na época da reprodução (FRANCISCO, 1997).

Nos jabutis, uma das principais características é o plastrão, que nos machos é côncavo e nas fêmeas é reto, ou mesmo convexo (SANTOS, 1994). Isso facilita o procedimento da cópula, de modo que o macho possa encaixar-se sobre a fêmea. O orifício cloacal nos machos está situado mais afastado do plastrão que nas fêmeas. Em função de as fêmeas porem ovos, suas placas anais formam um ângulo mais pronunciado que nos machos, facilitando, assim, a saída dos ovos, no momento da postura (FRANCISCO, 1997).

Nos cágados podemos observar que a cauda dos machos é nitidamente maior que a das fêmeas e também é possível observar que as placas anais das fêmeas têm disposição semelhantes às das fêmeas dos jabutis, para facilitar a postura (FRANCISCO, 1997).

O período reprodutivo é determinado pelas estações do ano e ocorre principalmente a partir do mês de outubro, tendo seu ápice em janeiro (SAÚDE ANIMAL, 2000).

Quando existe mais de um macho, eles vão disputar a fêmea batendo repetidamente seus cascos uns nos dos outros (SAÚDE ANIMAL, 2000).

Ao acasalar, o macho emite um chiado típico (SAÚDE ANIMAL, 2000). Os jabutis costumam enterrar os seus ovos em locais onde tenha muita luz solar e a terra deve ter uma consistência que lhes permita cavar (FOWLER, 1986). Os ovos dos jabutis não devem ser virados, pois não possuem os mesmos mecanismos de proteção interna existentes nos ovos das aves, podendo causar danos ao embrião. Os filhotes só começam a se alimentar com um mês de idade. Até lá, nutrem-se com a reserva vitelina que mantêm no abdômen ao saírem do ovo (SAÚDE ANIMAL, 2000).

\section{Prevenção de doenças}

A prevenção de doenças é o procedimento mais lógico, mais econômico e mais duradouro, quando se considera a saúde animal. Tão importante quanto tentar salvar a vida de um exemplar doente, é procurar evitar que outros animais do plantel sejam acometidos pela mesma enfermidade. No cativeiro, porém, as condições ambientais favorecem os surtos. A concentração de organismos patogênicos é maior, ocorre o maior contato entre diferentes espécies, e os erros nutricionais e de manejo, aliados ao estresse, acabam por enfraquecer a resistência orgânica e imunológica dos animais cativos (FRANCISCO, 1997).

A prevenção de doenças inclui uma higiene adequada dos recintos habitados pelos animais, devendo ser diária a limpeza. Os utensílios de cada terrário devem ser exclusivos, evitando carrear microrganismos de um local para outro. Comedouros e bebedouros devem ser limpos após o uso. Os desinfetantes à base de fenóis não devem ser usados, pois são normalmente ineficazes no combate a Pseudomonas, um microrganismo freqüente nos terrários. Um desinfetante eficiente e de baixo custo é o hipoclorito de sódio (água sanitária), diluído na proporção de 
$3 \%$ em desinfecções rotineiras. O agente químico de desinfecção deve permanecer em contato com as superfícies por 15 a 30 minutos, antes de serem enxaguadas (FRANCISCO, 1997).

A introdução de novos animais no recinto deve ser precedida pela quarentena, prevenindo a introdução de doenças nas espécies do plantel. Como regra, recomenda-se um período de 30 a 90 dias, em que exames laboratoriais e físicos devem ser realizados nos novos animais (FRANCISCO, 1997).

Para que mantenham uma boa saúde, evitando problemas como hipotermia ou hipertermia, é de fundamental importância que esses animais sejam mantidos dentro de sua temperatura de conforto que, para a maioria das espécies, varia, durante o dia de, $27,8^{\circ}$ a $31,1^{\circ} \mathrm{C}$ e, à noite, varia de 21,1 a $24,4^{\circ} \mathrm{C}$ (MADER, 1996).

\section{Doenças mais comuns no cativeiro doméstico}

Os animais no ambiente natural, diante das adversidades, apresentam o comportamento de luta ou fuga. Em cativeiro, pelo impedimento da fuga, são induzidos a uma condição de frustração profunda, o que pode levar à exaustão. Como medidas atenuantes é imprescindível um manejo e dietas adequados para se diminuir o estresse (BISPO e LANZOTTI, 1998).

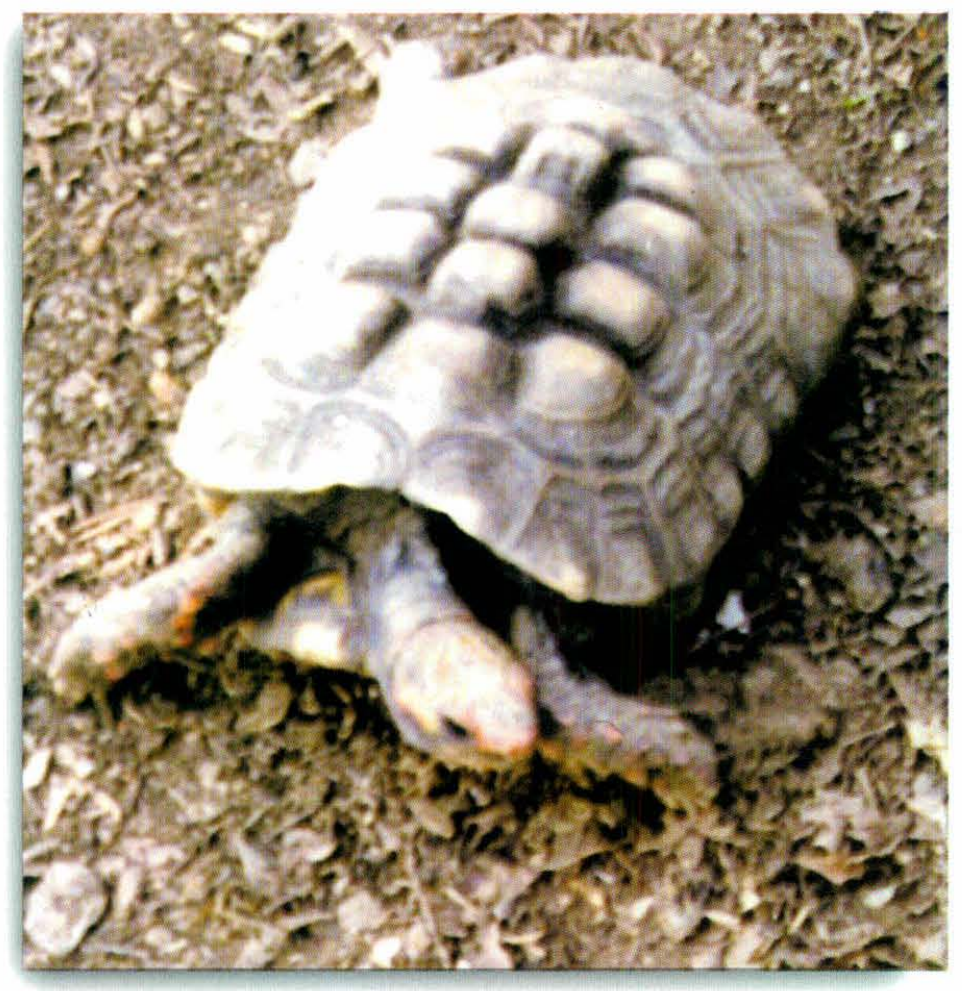

Figura 2. Geochelone carbonaria apresentando deformidade da carapaça devido a problemas nutricionais (Foto na Escola de Ecologia de São Caetano do Sul-SP).
O estresse é um estado que consome energia do organismo, é uma atividade intrínseca dos sistemas orgânicos e representa um fenômeno de adaptação (BISPO e LANZOTTI, 1998).

Deficiências nutricionais ou balanceamento inadequado dos alimentos, além de conduzir a quadro de estresse, pode levar à má formação do casco (Figura 2). Ao se readequar a alimentação, os animais podem voltar a ter uma boa saúde; contudo, os danos nos cascos permanecem (KIRK, 1988). Deformidades da carapaça e redução do crescimento têm sido observados em filhotes alimentados com dietas pobres em cálcio e com altos teores de proteína (MADER, 1996).

Lesões traumáticas na carapaça, podem ser provocadas por automóveis e ataques de cães ou gatos (KIRK, 1988). Os ferimentos provocados por outros animais domésticos necessitam de boa desinfecção e tratamento adequado orientado por médico veterinário (MENEZES, 2000).

Uma alta umidade do ambiente pode provocar problemas de carapaça em quelônios por causar amolecimento da queratina, ocorrendo, assim, a queda das placas córneas. A invasão de bactérias e fungos sob essas placas em desprendimento acelera o processo, fazendo com que elas caiam e a superfície óssea da carapaça fique exposta. Mais raramente esses desprendimentos das placas estão relacionados à insuficiência renal. O tratamento depende do grau de evolução da enfermidade; se apenas uma ou duas placas forem afetadas, o prognóstico é melhor. Utilizam-se fibra de vidro autoclavada e resina acrílica como materiais restauradores para a confecção de próteses (FRANCISCO, 1997).

A maioria das doenças da carapaça tem fundo bacteriano, uma grande variedade de bactérias gramnegativas e gram-positivas podem invadir a carapaça; a maior parte são patógenos oportunistas, usualmente habitantes da pele, do trato digestivo ou do solo, que podem causar infecções caso as circunstâncias favoreçam (falta de higiene, alimentação deficiente ou lesões). As principais bactérias gram-negativas encontradas nesses casos são: Pseudomonas, Aeromonas, Proteus, Serratia, Klebsiella, Escherichia coli; as gram-positivas são: Staphylococcus aureus e Streptococcus b-hemolíticos (KIRK, 1988).

Segundo BIRCHARD e SHERDING, (1998), a hipovitaminose D manifesta-se com sinais clínicos que incluem o raquitismo, a osteomalacia e cascos moles. Já a hipervitaminose D é causada por suplementos dietéticos exagerados ou exposição prolongada a lâmpa- 
FLOSI, F. M.; GARCIA, J. M.; PUGLIESE, C.; SANCHEZ, A. A.; KLAI, A. Manejo e enfermidades de quelônios brasileiros no cativeiro doméstico / Management and disease of Brazilian chelonians in urban captivity. / Rev. educ. contin. CRMV-SP / Continuous Education Journal CRMV-SP, São Paulo, volume 4, fascículo 2, p. 65 - 72, 2001.

das solares que podem levar à calcificação dos tecidos moles e à mobilização do cálcio dos ossos, resultando em osteopenia.

A hipovitaminose A é observada em jabutis jovens alimentados com dietas de insetos secos e alface. Os sinais clínicos são olhos fechados e edema de pálpebra. Pode ocorrer metaplasia escamosa no epitélio respiratório e nos ductos biliares (BIRCHARD e SHERDING, 1998).

A hipervitaminose A ocorre mais comumente em quelônios terrestres que têm em suas dietas uma alta concentração de carotenóides. Os sinais clínicos são: desenvolvimento de pele muito seca ou intensa descamação, com conseqüente perda severa de pele, expondo e infectando os tecidos musculares (FRANCISCO, 1997).

A enfermidade de maior ocorrência associada a parasitos é a miíase, causada pela infestação de larvas (FOWLER, 1986; KIRK, 1988). As moscas põem seus ovos em qualquer ferida, e os ovos poderão eclodir em 12 a 24 horas. Essas larvas carnívoras rapidamente invadirão o corpo do animal, produzindo incrível destruição. Os animais com lesão no casco precisam ficar longe das moscas (KIRK, 1988).

Os quelônios também podem apresentar infestações por endoparasitos, como membros da família Spirorchidae e Ascarídeos (FOWLER, 1986).

O prolapso de pênis é relativamente freqüente nos quelônios. Quando não há retração, ocorrem traumatismos, lesões e edemas que podem evoluir para isquemia, necrose e toxemia. Nos estágios iniciais é possível a redução do edema e a reposição para dentro da cloaca, em estágios mais avançados; quando o órgão já apresenta áreas de necrose, a cirurgia de amputação é necessária (FRANCISCO, 1997).

Outras lesões de pele podem ocorrer pela abrasão do ventre, do plastrão, da cauda, da cloaca e do pênis em pisos ásperos. Ocorrem feridas que podem evoluir para septicemia e morte (MOLINA, 1999; MENEZES, 2000).

Cágados em ambiente de água contaminada podem desenvolver uma doença cutânea ulcerativa septicêmica causada por bactérias. O quadro evolui para, hemorragias, anorexia, flacidez muscular e morte, caso o animal não seja convenientemente atendido (MENEZES, 2000).

Os quelônios criados em consorciação com outras espécies, principalmente mamíferos que possuem em sua flora intestinal enterobactérias que podem provocar doenças cutâneas ulcerativas, podem desenvolver quadros septicêmicos, como necrose do fígado, anorexia, caquexia e morte (MENEZES, 2000).
Os animais muito jovens são os mais susceptíveis a doenças e com maior índice de mortalidade (MOLINA, 1999; MENEZES, 2000).

As tartarugas também estão implicadas na transmissão de enterobactérias ao homem, como a Salmonella spp, de forma que alguns cuidados de higiene, como lavar as mãos após o manuseio do animal, devem ser executados com rigor, principalmente pelas crianças, cujo organismo é mais suscetível (FOWLER, 1997).

A Salmonella spp. faz parte da microflora intestinal dos quelônios (FRANCISCO, 1997; BIRCHARD e SHERDING, 1998). Quando um animal entra em estado de estresse ou doença, a resistência orgânica é diminuída e a bactéria torna-se patogênica para o animal hospedeiro. Sabe-se que a bactéria é encontrada nas fezes, na urina, nos ovos e na carne dos animais portadores, podendo causar gastroenterite, hepatite necrótica, pneumonia e septicemia. O tratamento é feito com antibióticos específicos (FRANCISCO, 1997).

Segundo ALLEN et al. (1993), as medicações são administradas aos répteis primariamente por via oral, subcutânea e intramuscular. $\mathrm{O}$ acesso venoso em muitas espécies é difícil ou impossível. A medicação oral pode ser administrada na comida, com mistura de uma dieta preparada, ou por intubação por uma sonda gástrica ou esofágica, mas, em algumas espécies de tartarugas, pode não ser possível a intubação. A aplicação intramuscular pode ser feita nos membros anteriores. A administração subcutânea é uma alternativa comum para pequenas espécies com pouca massa muscular e é feita na região do pescoço.

\section{Discussão}

Em seu habitat, a natureza encarrega-se de prover os animais com condições necessárias a seu desenvolvimento, reprodução e perpetuação da espécie. As relações inter e intra-espécies possuem particularidades e complexidades ainda distantes de serem perfeitamente compreendidas pelo homem.

O ser humano, quer seja pela degradação ambiental, quer seja pela captura de indivíduos para alimentação ou comércio, provoca graves alterações no ecossistema, o que pode determinar a extinção de espécies animais e vegetais fundamentais nessa interação entre os seres vivos.

É de fundamental importância a conscientização do homem para que não retire animais silvestres de seu habitat para criação doméstica.

Cabe aos médicos veterinários a orientação aos proprietários desses animais, para que estes possam ter suas necessidades básicas em cativeiro, evitando-se-lhes, assim, enfermidades e, conseqüentemente, o sofrimento e a morte. 


\section{SUMMARY}

Brazilian chelonians belong to the following families: Testudinidae (tortoises), Chelidae, Emydidae, Pelomedusidae, Kinosternidae (turtles and terrapins). Many species belonging to these families are kept in domestic captivity and need appropriate management, including nutrition provided by feed formulated to meet the nutritional requirements of each species. By doing so, one can prevent several diseases induced by inadequate management, such as the frequent shell deformities and vitamin deficiencies, especially those regarding vitamin A. The need to preserve these animals as well as their ecosystem is also stressed.

Key words: chelonians, management, feeding, disease.

\section{REFERÊECIAS}

1. ALLEN, D. G. et al. Handbook of veterinary drugs. Philadelphia: J. B. Lippincott 1993. 678 p.

2. ANGELIS, R. C. Fisiologia da nutrição. São Paulo: Edart, $1979,320 \mathrm{p}$.

3. BIANCO, E.R. et al. Tratado elemental de zoologia. México: Editorial Científica Latino Americana Lários, 1959. 737 p.

4. BIRCHARD, S. J.; SHERDING Manual Saunders - Clínica de pequenos animais. São Paulo: Roca, 1998. 1591 p.

5. BISPO, D. L.; LANZOTTI, V. M. B. Farmacologia do estresse. In: MAGALHÃES, H. M. (Org). Farmacologia veterinária, temas escolhidos. Guaíba: Livraria e Editora Agropecuária, 1998. 214p. p. $37-109$.

6. CENERINO, F. V. Utilização do recinto de quelônios aplicada à educação ambiental. In: SEMANA CIENTÍFICA DA UNIABC, 1., Santo André, 2000. Anais... Santo André: Universidade do Grande ABC, 2000. p. 92.

7. FARIA, T. N. Descrição da origem, trajeto e número das principais artérias do jabuti Geochelone carbonaria (Spix, 1824). 2000. 42 f. Dissertação (Mestrado em Anatomia dos Animais Domésticos) - Universidade de São Paulo, São Paulo.

8. FOWLER, M. E. Zoo and wild animal medicine. Philadelphia: W. B. Sauders, 1986. 1127 p.

9. FOWLER, M. E. Zoo veterinarian's workshop. São Paulo: Apostila, 1997.

10. FRANCISCO, L. R. Répteis do Brasil. São José dos Pinhais: Amaro, 1997. 208 p.

11. FUNDAÇÃO PARQUE ZOOLÓGICO DE SÃO PAULO, Fichas de alimentação. s.d.

12. HÖFLING, E. et al. Chordata: manual para um curso prático. São Paulo: Edusp, 1995. 242 p.

13. HOUAISS, A. Pequeno dicionário enciclopédico. Rio de Janeiro: Koogan Larousse, 1979. 1644 p.
14. KIRK, R. W. Atualização terapêutica veterinária. São Paulo: Manole, 1988. 1688 p.

15. MADER, D.R. Reptile medicine and surgery. Philadelphia: W. B. Saunders, 1996. 514 p.

16. MAYNARD, L. A.; LOOSLI, J. K. Nutrição animal. Rio de Janeiro: Freitas, 1974. 550 p.

17. MENEZES, S. R. Patologias induzidas por erros de manejo. Animal Pet, Campinas, v. 2, n. 6, p. 16, 2000.

18. MOLINA, F. B. Manejo e conservação de quelônios no campo e em cativeiro. In: ASPECTOS da Biologia e conservação de répteis, aves e mamíferos. Curso de difusão cultural. São Paulo: Fundação Parque Zoológico de São Paulo, 1999 .

19. SANTOS, E. Zoologia brasílica. Belo Horizonte: Vila Rica, 1994. $263 \mathrm{p}$.

20. SAÚDE ANIMAL. Jabuti - Geochelone carbonaria $e$ Geochelone denticulata. Disponível em: < http:// www.saudeanimal.com.br>. Acesso em: 2000.

21. SHIMIDT-NIELSEN, K. Fisiologia animal. DF: México: Uthea, 1965. 201p.

22. SOCIEDADE DE ZOOLÓGICOS DO BRASIL. Apostila. Sorocaba: SZB, 1991.

23. SPALATO, V. Situação atual e perspectivas dos estudos sobre quelônios no Brasil: análise dos resumos apresentados nos congressos brasileiros de 1983 a 1998. São Caetano do Sul: 1999. 42 f. Monografia (Graduação em Ciências Biológicas) - Universidade do Grande ABC.

24. VEITENHEIMER-MENDES, I. L. et al. Guia ilustrado de fauna e flora. Porto Alegre: Copesul / FZB, 1993. 229 p.

25. WOOD, D. W. Princípios de fisiologia animal. São Paulo: Polígono, 1973. 366 p. 